\title{
SIRT3-SOD2-ROS pathway is involved in linalool-induced glioma cell apoptotic death
}

\author{
Yanhao Cheng, Chao Dai ${ }^{\bowtie}$ and Jian Zhang \\ Department of Functional Neurosurgery, The People's Hospital of Linyi, Linyi 276003, Shandong, China
}

Glioma is the most prevalent type of adult primary brain tumor and chemotherapy of glioma was limited by drug-resistance. Linalool is an acyclic monoterpene alcohol possessing various pharmacological activities. The present study was conducted to evaluate the effect of linalool on glioma cell growth. The effect of linalool on cell viability in U87-MG cells was investigated and the results showed that linalool significantly reduced cell viability in a concentration- and time-dependent manner. In addition, exposure of the cells to linalool resulted in a concentration-dependent increase of TUNEL-stained cells, indicating the occurrence of apoptotic cell death. Linalool decreased mitochondrial oxygen consumption rate, increased the expression of Bax and Bak, reduced the expression of $\mathrm{Bcl}-2$ and $\mathrm{Bcl}-\mathrm{xl}$, and increased the activities of caspase 3 and caspase 9, leading to increase of apoptosis. Linalool resulted in a concentration-dependent decrease of SOD activity but had no significant effect on mRNA and protein expression of SOD2. Moreover, linalool resulted in a significant increase of the expression of acetylated SOD2. The mRNA and protein expression of SIRT3 was significantly inhibited by linalool. Immunoblot analysis showed that there was an evident protein/protein interaction between SOD2 and SIRT3 under normal condition. Linalool treatment significantly decreased the interaction between SOD2 and SIRT3. Overexpression of SIRT3 significantly inhibited linalool-induced increase of mitochondrial ROS production and apoptotic cell death, and decrease of cell viability. In summary, the data demonstrated that linalool exhibited inhibitory effect on glioma cells through regulation of SIRT3-SOD2-ROS signaling.

Key words: linalool, glioma, apoptotic cell death, SIRT3, SOD2

Received: 05 October, 2016; revised: 25 December, 2016; accepted: 05 January, 2017; available on-line: 02 June, 2017

e-mail: chao dai1132@163.com

Abbreviations: 7-ADD, 7-aminoactinomycin D; Bak, Bcl-2 antagonist killer 1; Bax, Bcl-2 associated $\mathrm{x}$ protein; $\mathrm{BCl}-2$, $\mathrm{B}$-cell lymphoma 2; BCl-xl, B-cell lymphoma-extra large; CCCP, carbonyl cyanide m-chlorophenylhydrazone; MTT, (3-4,5-dimethyl-2-thiazolyl)-2,5diphenyl-2-H-tetrazolium bromide; ROS, reactive oxygen species; SIRT3, sirtuin 3; SOD2, superoxide dismutase 2

\section{INTRODUCTION}

Glioma is the most prevalent type of adult primary brain tumor and is characterized by heterogeneity (Adamson et al., 2010; Ding et al., 2015; Vigneswaran et al., 2015). Glioma is composed of several different subtypes including grades I, II, III, and IV according to the WHO grading system by cytologic feature and malignancy degree (Fuller \& Scheithauer, 2007; Louis et al., 2007; Nakazato, 2008). Grade IV is the most malignant type of glioma and the glioblastoma multiform is the most aggressive primary brain tumor with a poor prognosis (Friedman et al., 2000). Epidemiological studies have shown that glioma accounts for approximately $40 \%$ of all primary brain and central nervous system tumors (Bondy et al., 2008; Goodenberger \& Jenkins, 2012; Ostrom et al., 2013). In particular, approximately $70-80 \%$ of all malignant brain tumors are glioma (Ohgaki, 2009; Omuro \& DeAngelis, 2013). In spite of recent advances in the treatment of glioma, almost $95 \%$ of patients die within 5 years (Grossman et al., 2010) and the median overall survival of glioma patients is only 14.6-17 months (Stupp et al., 2009). Patients with glioblastoma multiform only survive 10-15 months (Bondy et al., 2008). It is reported that approximately 13000 glioma patients die every year in the USA. To date, conventional treatments for glioma include surgical resection followed by radiotherapy and systemic temozolomide chemotherapy (Weller et al., 2013). Temozolomide, an alkylating agent, is used as the first line chemotherapeutic drug in clinical therapy of glioma (Friedman et al., 2000). However, there is gradually increasing drug-resistance with temozolomide treatment in recent years.

Linalool is an acyclic monoterpene alcohol found in essential oils from many aromatic plants, sage, lavender, rosewood, thyme and bergamot. Linalool is usually used as an additive for processed food and beverages and even more commonly as a fragrance ingredient in cosmetics, toiletries and household detergents (Letizia et al., 2003). It has been shown that linalool possesses anti-inflammatory, analgesic, local anaesthetic, antimicrobic, antibacterial and antiviral activities (Batista et al., 2010; Berliocchi et al., 2009; do Socorro et al., 2003; Peana et al., 2003; Peana et al., 2002). Since linalool is a member of the monoterpenoids family of compounds that are recognized as a group of potential chemopreventive compounds, it is considered to have chemopreventive activity. Experimental studies have shown that linalool could inhibit the growth of various human cancer cells (Bardon et al., 1998; Crowell, 1999; Jana et al., 2014; Paik et al., 2005; Russo et al., 2013). However, whether linalool can inhibit glioma proliferation is not known.

The present study was designed to evaluate the effect of linalool on glioma cell growth. We showed that linalool concentration-dependently decreased glioma cell viability and induced apoptotic cell death through regulating sirtuin 3 (SIRT3)-superoxide dismutase 2 (SOD2)reactive oxygen species (ROS) pathway.

\section{MATERIALS AND METHODS}

Chemicals and reagents. $\beta$-Actin was purchased from Santa Cruz Biotechnology Inc. (Shanghai, China). 
SOD2 and STAT3 antibodies were obtained from Cell Signaling Technology (Danvers, MA, USA). MitoSOX was obtained from Invitrogen (Carlsbad, CA, USA). Linalool and 3-[4,5-dimethylthiazol-2-yl]-2, 5-diphenyl tetrazolium bromide (MTT) were purchased from SigmaAldrich (St. Louis, MO, USA).

Cell culture and treatment. Human glioblastoma U87-MG cell line and normal human astrocyte cell line (HA1800) were purchased from the American Type Culture Collection (ATCC; Manassas, VA, USA). The cells were maintained in Dulbecco's modified Eagle's medium supplemented with $10 \%$ fetal bovine serum, 100 units/ $\mathrm{ml}$ penicillin, $100 \mu \mathrm{g} / \mathrm{ml}$ streptomycin, $1 \mathrm{mM}$ sodium pyruvate, and $1 \mathrm{mM}$ nonessential amino acids at $37^{\circ} \mathrm{C}$ in a $5 \% \mathrm{CO}_{2}$ incubator. For linalool treatment, the cells were exposed to indicated concentrations of linalool in serum-free medium for the indicated time.

Transfection of plasmids. SIRT3 plasmids were synthesized commercially (GenePharma, China). Cell transfection was performed using lipofectamine 2000 (Invitrogen, Carlsbad, CA, USA) according to the manufacturer's protocols. Empty vectors were used as the negative control.

Cell viability and cell death. After the treatment, cell viability was assessed by the MTT assay. $0.5 \mathrm{mg} / \mathrm{ml}$ MT'T was added to each well and incubated for $4 \mathrm{~h}$. After aspiration of the supernatants, formazan crystals were dissolved in dimethylsulfoxide. The absorbance at 550 $\mathrm{nm}$ was measured using a plate reader. For the detection of cell death, cells were stained with 7-AAD and analyzed using flow cytometer (BD, C6, USA). The results were show as percentage of 7-AAD-positive cells.

Apoptosis. Apoptosis was analyzed using an In Situ Cell Death Detection Kit (Roche; Basel, Switzerland) by flow cytometry. Briefly, after the treatment, the cells were harvested and then stained with TUNEL followed by analysis on a BD flow cytometer (San Jose, CA, USA). The percentage of TUNEL-stained cells was analyzed. The results of apoptotic cell death were shown as folds of the control.

ROS determination. Mitochondrial ROS level was measured using the MitoSOX probe. In brief, the cells were cultured in a special dish for the observation under confocal microscope. After the treatment, the cells were incubated with $500 \mathrm{nM}$ MitoSOX in serum-free medium for $20 \mathrm{~min}$ at $37^{\circ} \mathrm{C}$ in a $5 \% \mathrm{CO}_{2}$ incubator. Fluorescence was recorded using a confocal microscope (Olympus, Japan). Fluorescence intensity was also calculated and shown as folds of the control.

Mitochondrial oxygen consumption. Mitochondrial oxygen consumption was determined as previously reported (Hao et al., 2004). In brief, the cells were suspended in the respiratory medium $[250 \mathrm{mM}$ sucrose, $20 \mathrm{mM}$ HEPES, $10 \mathrm{mM} \mathrm{MgCl}$, $5 \mathrm{mM} \mathrm{KH} \mathrm{PO}_{4}, 0.1 \%$ bovine serum albumin, $1 \mathrm{mM}$ ADP ( $\mathrm{pH}$ 7.4)]. Oxygen consumption was measured with the Hansatech oxygen electrode (Norfolk, United Kingdom) in a thermojacked sample chamber stirred with a magnetic stirrer. One-ml sample chamber was filled with $1.0 \mathrm{ml}$ of cell suspension containing $10^{7}$ cells. The respiratory rate was monitored for $3 \mathrm{~min}$ and then $10 \mu \mathrm{M}$ CCCP and $25-100 \mu \mathrm{M}$ linalool were added to the suspension and the oxygen content was recorded for another 3 min. Oxygen consumption was calibrated with air-saturated respiratory medium assuming $390 \mathrm{ng}$ atoms $\mathrm{O}_{2} / \mathrm{ml}$. The respiratory rate was expressed as nanogram atoms of $\mathrm{O}_{2}$ per minute per $10^{7}$ cells.

Immunoblot analysis. The cells were harvested and then lysed in RIPA buffer (Beyotime Biotechnology; Ji- angsu, China) with protease inhibitor and phosphatase inhibitors. Thereafter, the lysates were centrifuged at $12000 \mathrm{rpm}$ at $4^{\circ} \mathrm{C}$ for $10 \mathrm{~min}$. Protein concentration in the supernatant was determined using BCA assay kit (Thermo Fisher Scientific, USA). Lysates $(20 \mu \mathrm{g})$ were denatured and separated on $10 \%$ or $15 \%$ polyacrylamide/SDS gels. Separated proteins were then transferred onto a NC membrane (Millipore, USA). After blocking in 5\% non-fat dry milk in TBST at room temperature for $1 \mathrm{~h}$, the membranes were incubated with primary antibodies overnight at $4^{\circ} \mathrm{C}$. The membranes were then incubated with the secondary antibody conjugated to HRP (Thermo Fisher Scientific; Shanghai, China) for $1 \mathrm{~h}$ at room temperature. Bands were visualized by the chemiluminescence reaction using an ECL detection system (Thermo Fisher Scientific; Shanghai, China), followed by capture using BIORAD Imaging Systems (BIORAD, USA).

RNA isolation and quantitative real-time reverse transcription-polymerase chain reaction (RT-qPCR). Total RNA was extracted from cultured cells using Trizol (Invitrogen, Carlsbad, CA, USA) according to the manufacturer's instructions. RNA concentration was determined using microplate reader and the quality of the mRNA was detected using A260/A280 readings. cDNA was synthesized from 500 ng RNA using a random primer and a Reverse Transcriptase Kit (TIANGEN, China). mRNA level of target gene was quantified by RT-qPCR system using SYBR Green reagents (TaKaRa, Japan) in a BIORAD Cycling Biosystem. The relative expression was analyzed using the the comparative cycle threshold $\left(C_{T}\right)\left(2^{-\Delta \Delta} C T\right)$ method method, compared with the endogenous controls. Amplification conditions were as follows: initial step at $94^{\circ} \mathrm{C}$ for $5 \mathrm{~min}$, followed by 40 cycles of denaturation at $94^{\circ} \mathrm{C}$ for $30 \mathrm{~s}$, annealing at $63^{\circ} \mathrm{C}$ for $30 \mathrm{~s}$, and then extension at $72^{\circ} \mathrm{C}$ for $10 \mathrm{~s}$. $\beta$-Actin was used as the housekeeping gene.

Statistical analysis. All data were presented as the mean \pm S.E.M. All experiments were conducted at least in triplicates. Data analysis was performed using GraphPad Software. One-way analysis of variance (ANOVA) was used to measure the significance between more than two groups, followed by a Dunnett's $t$-test for multiple comparisons. $P<0.05$ was considered to be statistically significant.

\section{RESULTS}

\section{Linalool induced cytotoxicity in U87-MG cells}

To evaluate the possible effect of linalool on glioma cell growth, U87-MG cells were exposed to $25-100 \mu \mathrm{M}$ linalool for $24-72 \mathrm{~h}$ and the effect of linalool on cell viability was investigated. The results showed that linalool significantly reduced cell viability in U87-MG cells in a concentration- and time-dependent manner (Fig. 1A). Next, we evaluated the effect of linalool on cell death in U87-MG cells. We showed (Fig. 1B) that linalool dose- and time-dependently increased the percentage of 7-AAD-positive cells, indicating the induction of cell death. The effect of linalool on apoptotic cell death was examined. As shown in Fig. 1C and Fig. 1D, exposure of the cells to linalool resulted in concentration-dependent increase of TUNEL-stained cells, indicating the occurrence of apoptotic cell death. Furthermore, the differential sensitivities to linalool-induced cytotoxicity between glioblastoma U87-MG cells and normal human astrocyte cells were determined. As shown in Fig. 1E, glioblas- 

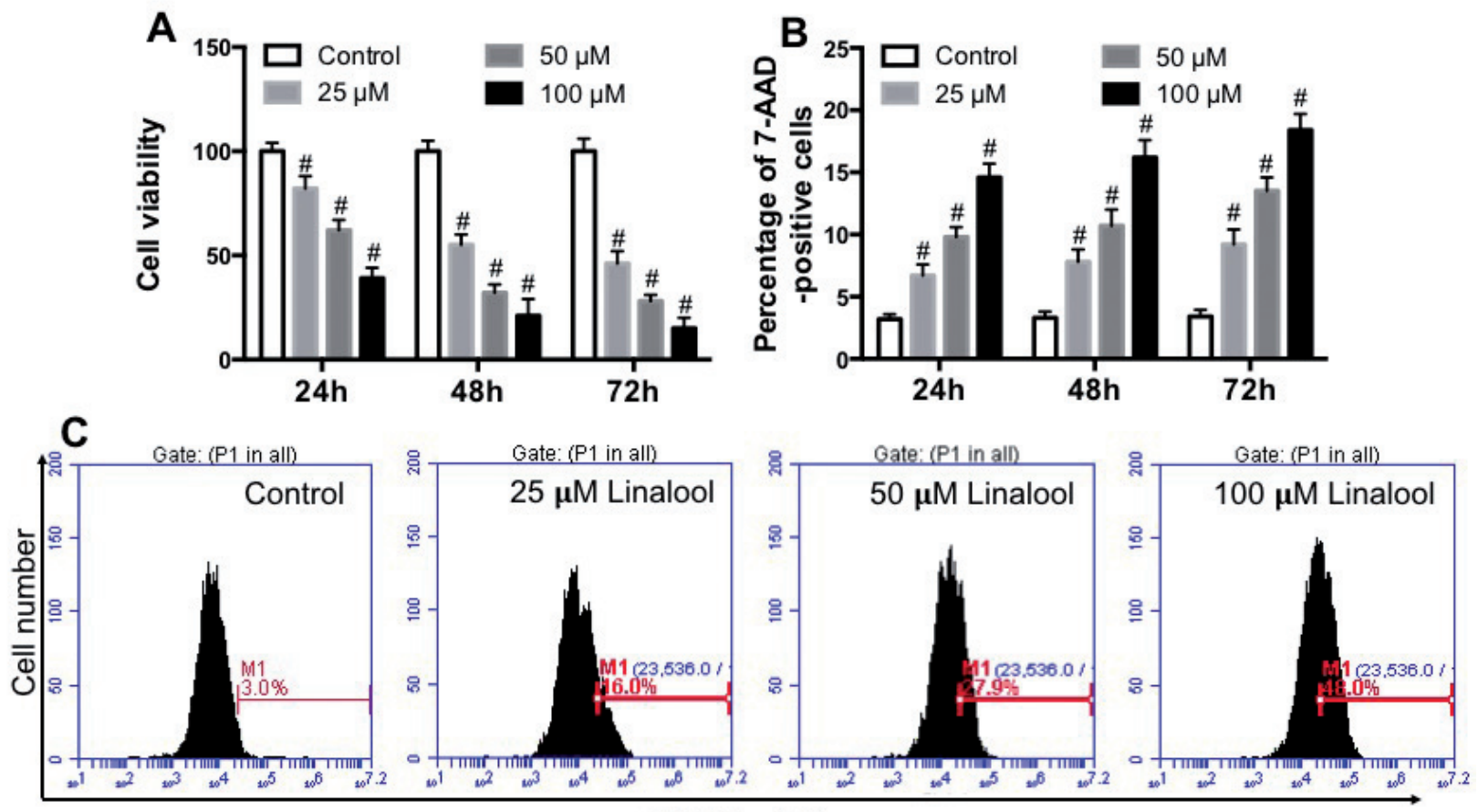

TUNEL staining
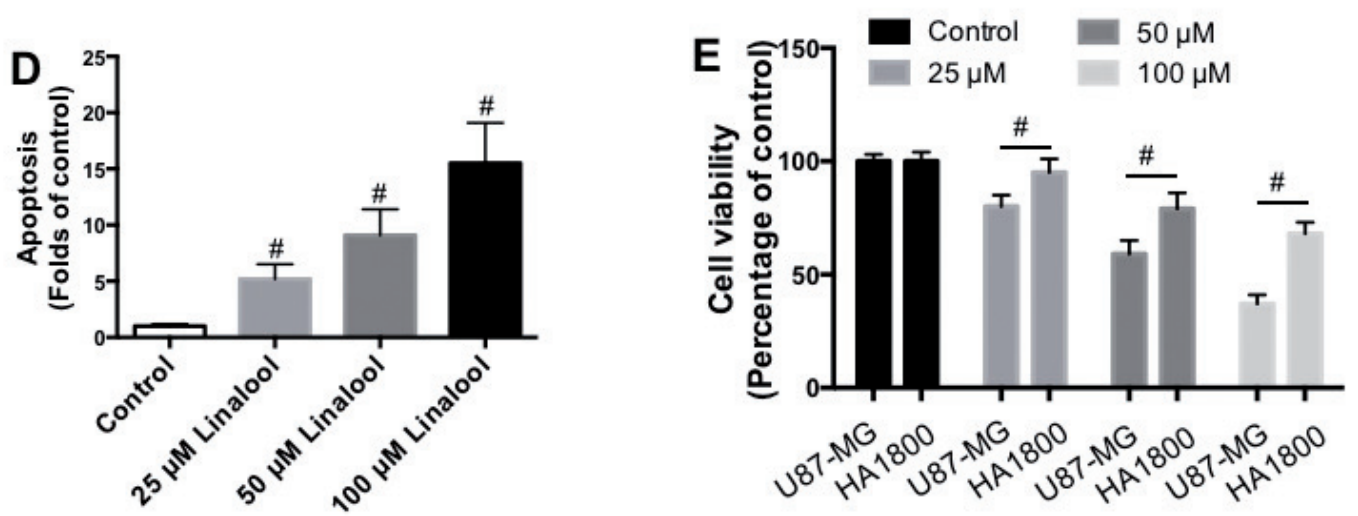

Figure 1. Effect of linalool on cell viability and apoptosis.

U87-MG cells were exposed to $25-100 \mu \mathrm{M}$ linalool for 24,48 and $72 \mathrm{~h}$. (A) Cell viability was determined by MTT assay. Cell death was indicated by staining with 7-AAD and analyzed using flow cytometry. (A) Viable cells. (B) Percentage of dead (7-AAD-positive) cells. (C) Apoptosis evaluated by TUNEL assay using flow cytometry. (D) Statistical analysis of apoptosis shown as folds of control. (E) U87-MG cells and HA1800 cells were exposed to $25-100 \mu \mathrm{M}$ linalool for $24 \mathrm{~h}$ and cell viability was determined by MTT. \#p<0.05 versus control.

toma cells were more sensitive to linalool-induced cytotoxicity. The results demonstrated that linalool exhibited a relatively cell-specific inhibitory effect on glioma cell viability through inducing apoptotic cell death.

\section{Linalool activated mitochondrial apoptotic pathway in U87-MG cells}

In the next step, we evaluated the effect of linalool on mitochondrial apoptotic pathway. In Fig. 2A, we showed that linalool exposure resulted in a concentration-dependent decrease of mitochondrial oxygen consumption rate in the presence of carbonyl cyanide m-chlorophenylhydrazone (CCCP), a classic uncoupler. In addition, linalool increased the mRNA expression of Bcl-2 associated $\mathrm{x}$ protein (Bax) and $\mathrm{Bcl}-2$ antagonist killer 1 (Bak) which were apoptosis-inducing factors, but reduced the
mRNA expression of apoptosis-inhibitory factors including B-cell lymphoma 2 (Bcl-2) and B-cell lymphomaextra large (Bcl-xl) (Fig. 2B, C, D, and E). Moreover, linalool increased the activities of caspase 9 and caspase 3 in a concentration-dependent manner (Fig. 2F and G). These results indicated that linalool activated mitochondrial apoptotic pathway in U87-MG cells.

\section{Linalool promoted mitochondrial ROS generation in U87-MG cells}

Mitochondrial ROS generation is considered to be an important contributor of mitochondrial apoptosis. We next evaluated the effect of linalool exposure on ROS production in mitochondria. The results showed that linalool significantly increased MitoSOX-staining in U87MG cells (Fig. 3), indicating that linalool increased mito- 

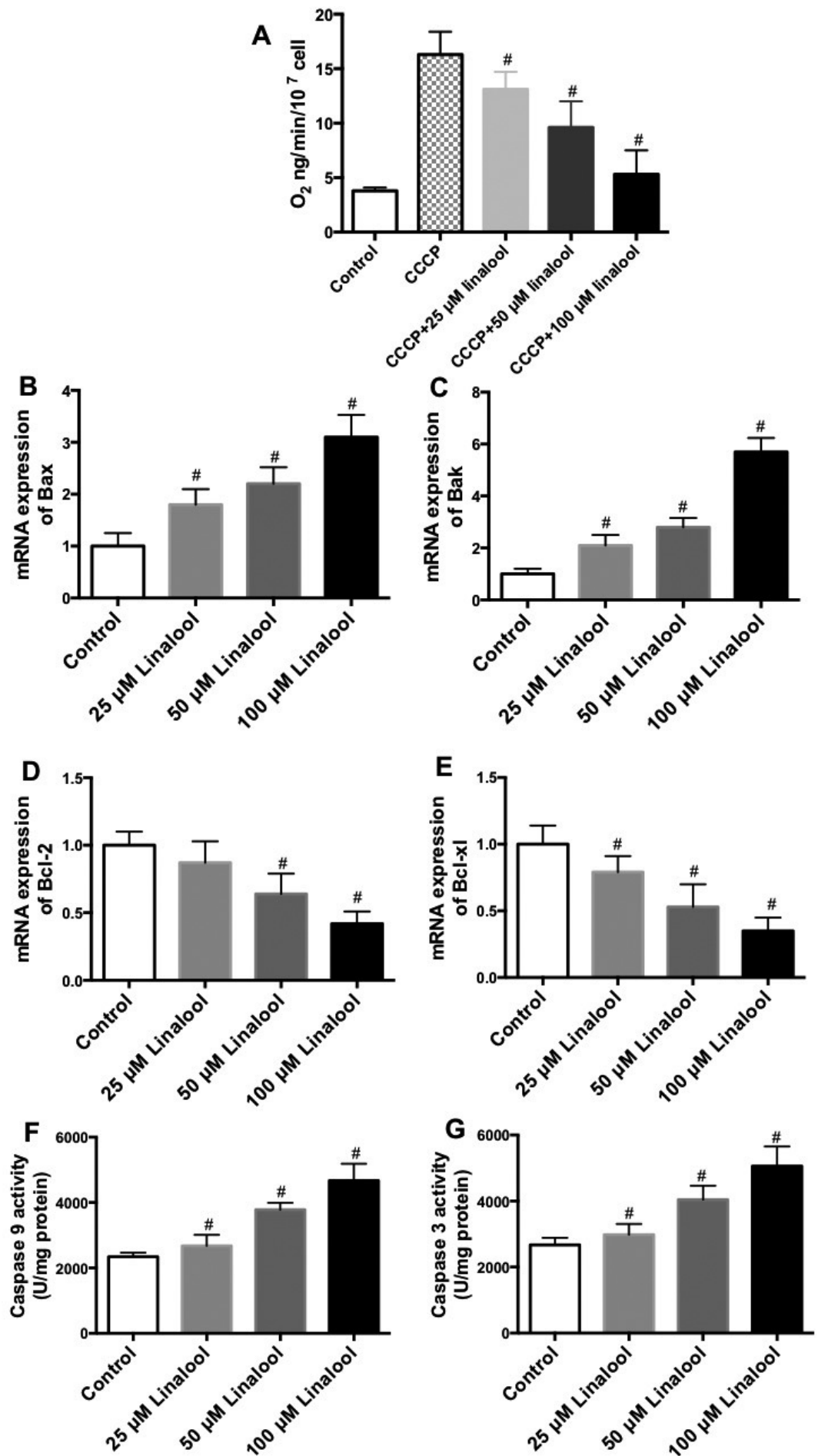

Figure 2. Effect of linalool on mitochondrial function and mitochondrial apoptotic pathway.

U87-MG cells were exposed to 25-100 $\mu \mathrm{M}$ linalool for $24 \mathrm{~h}$. (A) Mitochondrial function was assessed by oxygen consumption in the presence of CCCP. (B, C, D and E) mRNA expression of Bax, Bak, Bcl-2, and Bcl-xl was determined by RT-qPCR. (F and G) Activities of caspase 9 and caspase 3 were evaluated by commercial kits. $\# p<0.05$ versus control.

chondrial ROS level which may cause activation of the mitochondrial apoptotic pathway.

\section{Linalool affected the acetylation and activity of SOD2 in U87-MG cells}

SOD2 is an important antioxidant enzyme located in mitochondria and plays a critical role in protecting mitochondria against potential oxidative insult. We examined the effect of linalool exposure on SOD2 expres- sion and total SOD activity. We showed that linalool resulted in a concentration-dependent decrease of SOD activity (Fig. 4A). However, linalool had no significant effect on the mRNA and protein expression of SOD2 (Fig. 4B and C). Moreover, linalool resulted in a significant increase of the expression of acetylated SOD2 (Fig. 4C), indicating that linalool reduced SOD2 activity through induction of acetylation. 

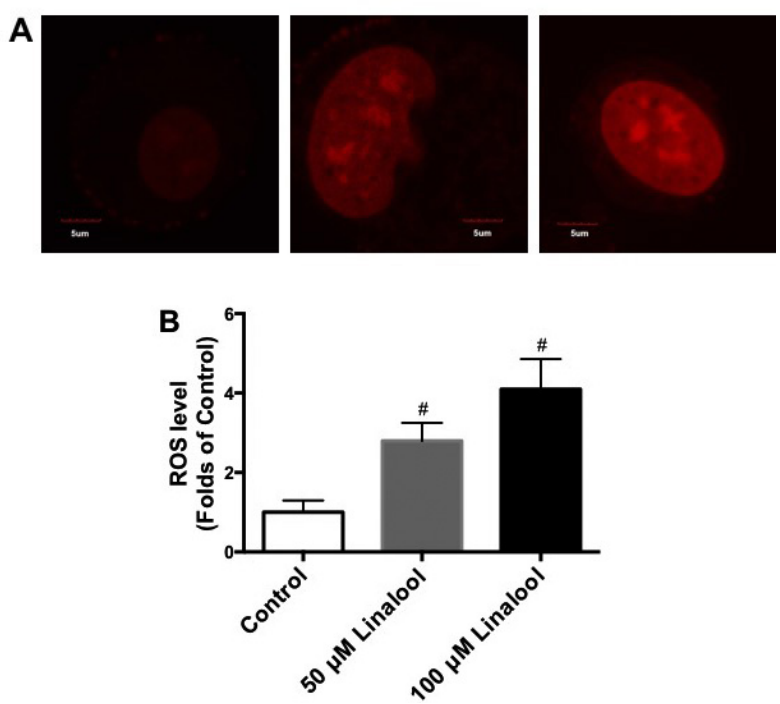

Figure 3. Effect of linalool on mitochondrial ROS level.

U87-MG cells were exposed to $50-100 \mu \mathrm{M}$ linalool for $24 \mathrm{~h}$. Cells were stained with MitoSOX and then observed using a confocal microscope. Representative images are presented $(\mathbf{A})$ and statistical analysis of the florescence is shown (B). $\# p<0.05$ versus control.

\section{Linalool decreased SIRT3 expression in U87-MG cells}

SIRT3 is an important deacetylase which plays key roles in the regulation of various processes. In our study, we further examined whether linalool affected SIRT3 expression and thus altered SOD2 activity. As shown in Fig. $5 \mathrm{~A}$ and $\mathrm{B}$, the mRNA and protein expression of SIRT3 was significantly reduced by linalool. Immunoblot analysis showed that there was an evident protein/protein interaction between SOD2 and SIRT3 in control U87-MG cells. Linalool treatment significantly decreased the interaction between SOD2 and SIRT3 (Fig. 5C), indicating that the decrease of SIRT3 expression contributed to the increase of SOD2 acetylation. To test the role of decrease of SIRT3 expression in linalool-induced cell death, the cells were transfected with plasmids expressing SIRT3. The results showed that overexpression of SIRT3 significantly inhibited linalool-induced reduction of mitochondrial ROS level, as reflected by decrease of MitoSOX staining in cells (Fig. 5D). Moreover, overexpression of SIRT3 significantly inhibited the decrease of oxygen respiration in the presence of CCCP induced by linalool (Fig. 5E). Overexpression of SIRT3 increased the oxygen uptake compared with empty plasmids (Fig. 5E). Overexpression of SIRT3 significantly inhibited linalool-induced increase of apoptotic cell death and the decrease of cell viability (Fig. 5F and $\mathrm{G})$. The results demonstrated that decrease of SIRT3 was involved in linalool-induced inhibitory effect on glioma cell viability (Fig. 6).

\section{DISCUSSION}

Previous studies have shown that linalool possesses anti-tumor effects in several types of cancer (Bardon et al., 1998; Crowell, 1999; Jana et al., 2014; Paik et al., 2005; Russo et al., 2013). In this study, we evaluated the effect of linalool on glioma cell viability and found that linalool exhibited inhibitory effects on U87-MG cells, indicating that linalool also possessed an anti-tumor effect in glioma. It is suggested that linalool exhibits broad chemotherapeutic activities. Moreover, we found that glioblastoma cells were more sensitive to linalool-induced cytotoxicity, compared with normal human astrocyte cells. The results demonstrated that linalool exhibited a relatively cell-specific cytotoxicity in glioblastoma cells, increasing the potential of linalool becoming a chemotherapeutic agent for glioblastoma. However, the mechanisms underlying the differential sensitivities of glioblastoma cells and normal human astrocyte cells to linalool needs to be elucidated.

Tumor cell growth is characterized by uncontrolled balance between proliferation and cell death. Promotion
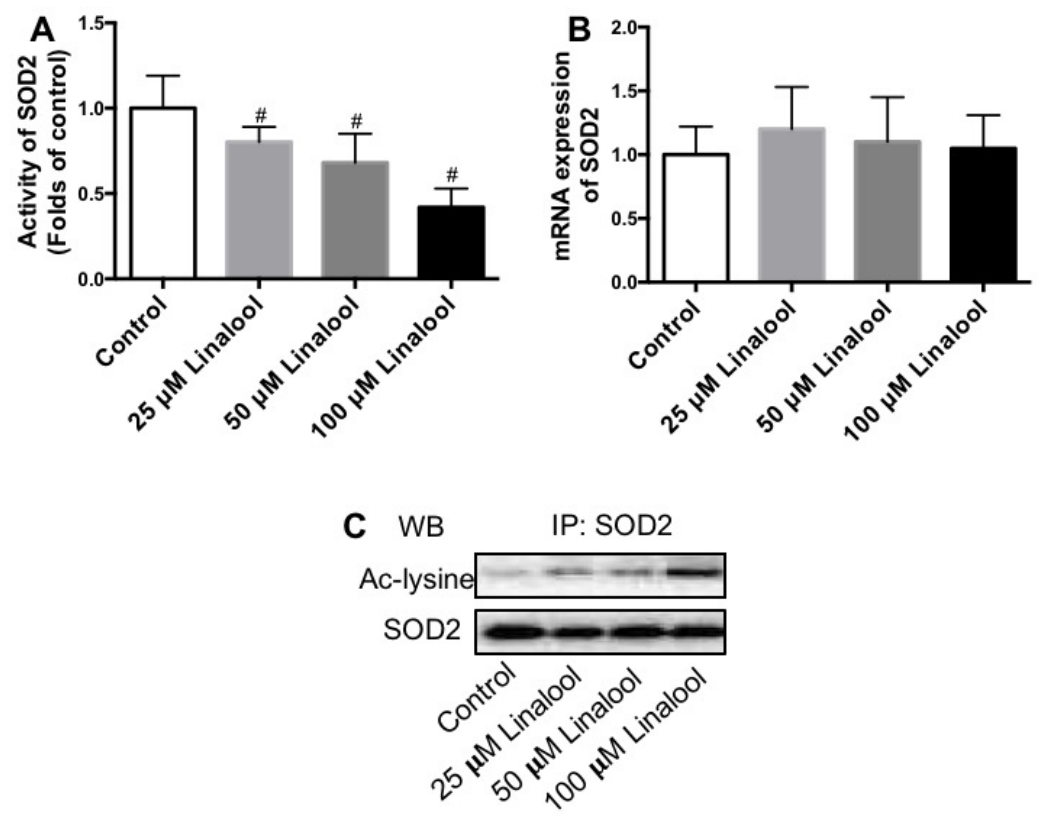

Figure 4. Effect of linalool on SOD2 expression and activity.

U87-MG cells were exposed to 25-100 $\mathrm{MM}$ linalool for $24 \mathrm{~h}$. (A) SOD activity was examined using a commercial kit and expressed as folds of control. (B) mRNA expression of SOD2 was determined by RT-qPCR. (C) Acetlytion of SOD2 was examined by immunoblot analysis. $\# p<0.05$ versus control. 


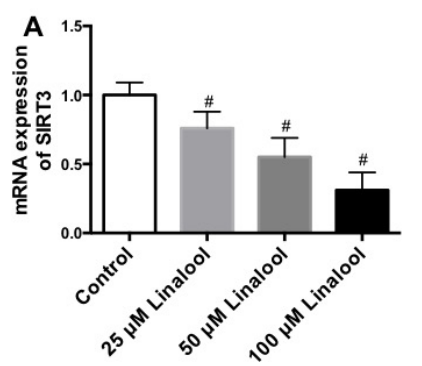

B

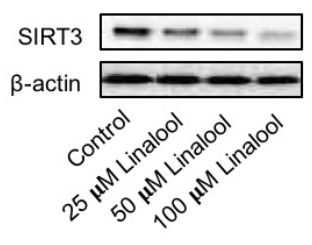

C

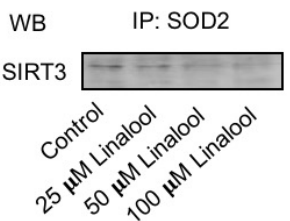

D
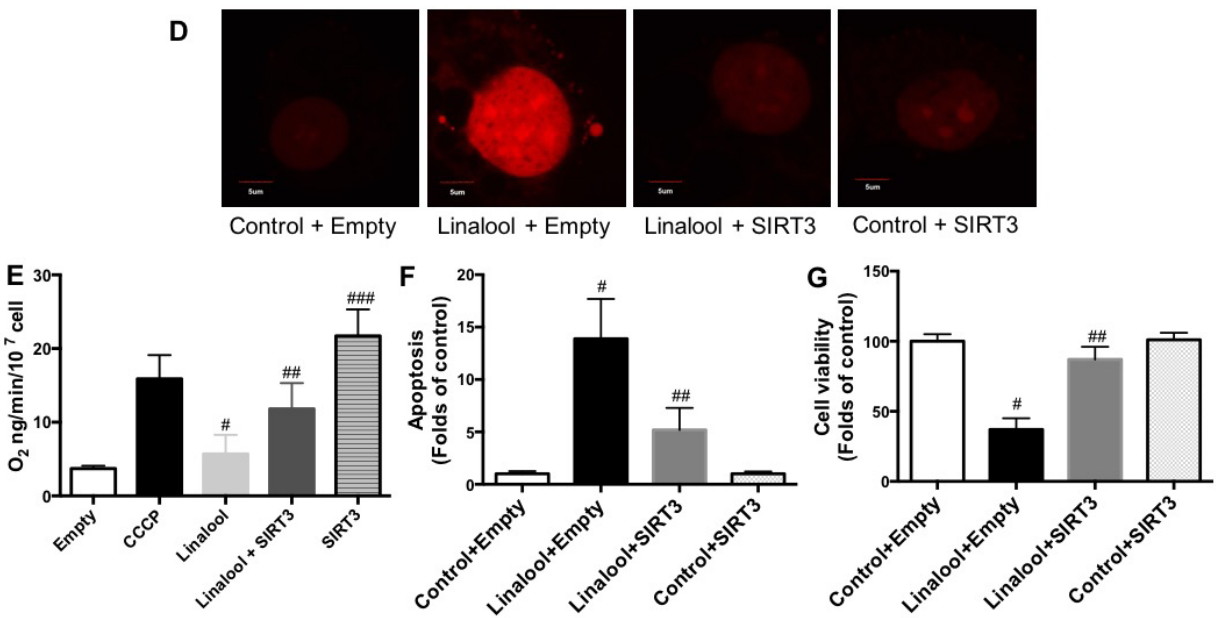

Figure 5. Effect of linalool on SIRT3 and SOD2 interaction.

U87-MG cells were exposed to $25-100 \mu \mathrm{M}$ linalool for $24 \mathrm{~h}$. (A and B) mRNA and protein expression of SIRT3 was examined. (C) Protein/protein interaction between SOD2 and SIRT3 was determined by immunoblot detection. U87-MG cells were transfected with SIRT3 plasmid and then exposed to $100 \mu \mathrm{M}$ linalool for $24 \mathrm{~h}$. (D) Cells were stained with MitoSOX and then observed using a confocal microscope. Representative images are presented. (E) Cell respiration in the presence of CCCP was determined. (F) Apoptosis was evaluated by TUNEL assay using flow cytometry and statistical analysis of apoptosis was conducted and results were shown as folds of control. (G) Cell viability was determined by MTT assay. $\# p<0.05$ versus control. \#\# $p<0.05$ versus linalool treatment.

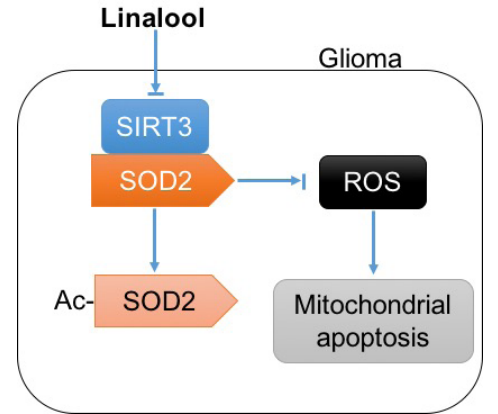

Figure 6. Schematic figure of the mechanism underlying linalool-induced glioma cell apoptotic death.

of apoptotic cell death is an important strategy for cancer intervention. The mitochondrial "intrinsic" pathway is a crucial pathway leading to apoptosis. Mitochondrial apoptotic pathway is regulated by a variety of factors. On the one side, proteins of the $\mathrm{Bcl}-2$ family, such as $\mathrm{Bcl}-2$ and $\mathrm{Bcl}-\mathrm{xl}$, function to prevent the apoptotic death (Adams \& Cory, 1998; Danial, 2007; Youle \& Strasser, 2008). The pro-apoptotic members, such as Bak and Bax, activate the release of apoptogenic molecules from the mitochondrial intermembrane space (Kuwana et al., 2002; Lindsten et al., 2000). The activation of caspases is the central downstream event, leading to the cleavage of substrates and final death of cell (Salvesen, 2002; Stennicke et al., 1998). Previous studies have shown that linalool could induce apoptosis in several cancer cells (Cerchiara et al., 2015; Chang \& Shen, 2014; Chang et al.,
2015; Gu et al., 2010). In the present study, we evaluated the effect of linalool on mitochondrial function and the apoptotic pathway. We examined the oxygen consumption using intact cells in $250 \mathrm{mM}$ sucrose. Although the $250 \mathrm{mM}$ sucrose medium did not represent a milieu in which living cells feel comfortable, since the effect of linalool on oxygen consumption was investigated in the presence of the uncoupler CCCP (which penetrates the membrane) and the experiment was short lasting (which means that the cells were still alive in spite of the unfavourable medium), this experiment can be accepted. We found that linalool decreased oxygen consumption, increased Bax and Bak expression, decreased Bcl-2 and $\mathrm{Bcl}-\mathrm{xl}$ expression and increased caspase 3 and 9 activities. The results of our study demonstrated that linalool exhibited a significant proapoptotic effect in glioblastoma cells through activation of mitochondrial apoptotic pathway. The results indicated that the proapoptotic effect of linalool was involved in the anti-tumor effects against glioma.

The mitochondrial function is prone to increased level of ROS and elevation of mitochondrial ROS generation is the major cause of mitochondrial apoptosis (Gupta et al., 2009). Our results indicated an important role of ROS in linalool-induced proapoptotic effect in glioblastoma cells. In previous studies, it has been suggested that linalool possesses both antioxidant and prooxidant effects (Chen et al., 2011; Han et al., 2016; Mimica-Dukic et al., 2010; Usta et al., 2009). The results indicated that the effect of linalool on ROS may be cell-specific. It may also be attributed to the dose-dependent effect of linalool. In a cell, there are a battery of antioxidant 
enzymes that are responsible for the elimination of ROS. In particular, SOD2 is an important antioxidant enzyme for controlling mitochondrial redox balance. SOD2 catalyzes the dismutation of superoxide into water and hydrogen peroxide. Our results suggested that linalool induced a post-translational modification of SOD2, leading to no significant changes of SOD2 expression but reduction of SOD2 activity. Acetylation and deacetylation are important mechanisms responsible for the regulation of various processes through post-translational modulation (Tao et al., 2016). SIRT3 is a mitochondria-localized deacetylase and it is reported that SIRT3 could regulate SOD2 through deacetylation (Pi et al., 2015). In response to calorie restriction, SIRT3 reduces cellular ROS levels which is dependent on SOD2 (Qiu et al., 2010). SIRT3 deacetylates two critical lysine residues on SOD2 and promotes its antioxidant activity and the ability to reduce ROS level (Qiu et al., 2010). Our findings provided a new evidence for SIRT3-induced deacetylation of SOD2 and confirmed that dowregulation of SIRT3, increase of the acetlytion of SOD2 and ROS were involved in linalool-induced anti-tumor effects in glioma.

In summary, we found that linalool exhibited inhibitory effects on glioma cells through regulation of SIRT3SOD2-ROS signaling. However, further studies are needed to evaluate whether linalool-induced regulation of SIRT3-SOD2-ROS in glioblastoma cells and normal human astrocyte cells are different. There is another weakness, namely that linalool was used in very high concentrations in the study. Thus further studies are needed to examine the anti-tumor effects of relatively low doses of linalool. Overall, our findings identify linalool as a novel potential treatment option for glioma and SIRT3-SOD2ROS axis as a novel therapeutic target.

\section{Conflict of Interest}

The authors declare that there are no conflicts of interest.

\section{REFERENCES}

Adams JM, Cory S (1998) The Bcl-2 protein family: arbiters of cell survival. Science 281: 1322-1326. doi: 10.1126/science.281.5381.1322.

Adamson DC, Rasheed BA, McLendon RE, Bigner DD (2010) Central nervous system. Cancer Biomark 9: 193-210. doi: 10.3233/cbm-20110177

Bardon S, Picard K, Martel P (1998) Monoterpenes inhibit cell growth, cell cycle progression, and cyclin D1 gene expression in human breast cancer cell lines. Nutr Cancer 32: 1-7. doi: 10.1080/01635589809514708

Batista PA, Werner MF, Oliveira EC, Burgos L, Pereira P, Brum LF, Story GM, Santos AR, (2010) The antinociceptive effect of (-)-linalool in models of chronic inflammatory and neuropathic hypersensitivity in mice. I Pain 11: 1222-1229. doi: 10.1016/j.jpain.2010.02.022

Berliocchi L, Russo R, Levato A, Fratto V, Bagetta G, Sakurada S, Sakurada T, Mercuri NB, Corasaniti MT (2009) (-)-Linalool attenuates allodynia in neuropathic pain induced by spinal nerve ligation in c57/bl6 mice. Int Rev Neurobiol 85: 221-235. doi: 10.1016/S00747742(09)85017-4

Bondy ML, Scheurer ME, Malmer B, Barnholtz-Sloan JS, Davis FG, Il'yasova D, Kruchko C, McCarthy BJ, Rajaraman P, Schwartzbaum JA, Sadetzki S, Schlehofer B, Tihan T, Wiemels JL, Wrensch M, Buffler PA (2008) Brain tumor epidemiology: consensus from the Brain Tumor Epidemiology Consortium. Cancer 113: 1953-1968. doi: $10.1002 /$ cncr.23741

Cerchiara T, Straface SV, Brunelli E, Tripepi S, Gallucci MC, Chidichimo G (2015) Antiproliferative effect of linalool on RPMI 7932 human melanoma cell line: ultrastructural studies. Nat Prod Commun 10: $547-549$

Chang MY, Shen YL (2014) Linalool exhibits cytotoxic effects by activating antitumor immunity. Molecules 19: 6694-6706. doi: 10.3390/ molecules19056694

Chang MY., Shieh DE, Chen CC, Yeh CS, Dong HP (2015) Linalool Induces Cell Cycle Arrest and Apoptosis in Leukemia Cells and Cervical Cancer Cells through CDKIs. Int J Mol Sii 16: 2816928179. doi: 10.3390/ijms161226089

Chen X, Hopke PK, Carter WP (2011) Secondary organic aerosol from ozonolysis of biogenic volatile organic compounds: chamber studies of particle and reactive oxygen species formation. Environ Sci Technol 45: 276-282. doi: 10.1021/es102166c

Crowell PL (1999) Prevention and therapy of cancer by dietary monoterpenes. I Nutr 129: 775s-778s

Danial NN (2007) BCL-2 family proteins: critical checkpoints of apoptotic cell death. Clin Cancer Res 13: 7254-7263. doi: 10.1158/10780432.ccr-07-1598

Ding Z, Liu Y, Yao L, Wang D, Zhang J, Cui G, Yang X, Huang $\mathrm{X}$, Liu F, Shen A (2015) Spy1 induces de-ubiquitinating of RIP1 arrest and confers glioblastoma's resistance to tumor necrosis factor (TNF-alpha)-induced apoptosis through suppressing the association of CLIPR-59 and CYLD. Cell Cycle 14: 2149-2159. doi: 10.1080/15384101.2015.1041688

do Socorro SRMS, Mendonca-Filho RR, Bizzo HR, de Almeida Rodrigues I, Soares RM, Souto-Padron T, Alviano CS, Lopes AH (2003) Antileishmanial activity of a linalool-rich essential oil from Croton cajucara. Antimicrob Agents Chemother 47: 1895-1901. doi: 10.1128/ AAC.47.6.1895-1901.2003

Friedman HS, Kerby T, Calvert H (2000) Temozolomide and treatment of malignant glioma. Clin Cancer Res 6: 2585-2597

Fuller GN, Scheithauer BW (2007) The 2007 Revised World Health Organization (WHO) Classification of Tumours of the Central Nervous System: newly codified entities. Brain Pathol 17: 304-307. doi: 10.1111/j.1750-3639.2007.00084.x

Goodenberger ML, Jenkins RB (2012) Genetics of adult glioma. Cancer Genet 205: 613-621. doi: 10.1016/j.cancergen.2012.10.009

Grossman SA, Ye X, Piantadosi S, Desideri S, Nabors LB, Rosenfeld M, Fisher J (2010) Survival of patients with newly diagnosed glioblastoma treated with radiation and temozolomide in research studies in the United States. Clin Cancer Res 16: 2443-2449. doi: 10.1158/1078-0432.CCR-09-3106

Gu Y, Ting Z, Qiu X, Zhang X, Gan X, Fang Y, Xu X, Xu R (2010) Linalool preferentially induces robust apoptosis of a variety of leukemia cells via upregulating p53 and cyclin-dependent kinase inhibitors. Toxicology 268: 19-24. doi: 10.1016/j.tox.2009.11.013

Gupta S, Kass GE, Szegezdi E, Joseph B (2009) The mitochondrial death pathway: a promising therapeutic target in diseases. J Cell Mol Med 13: 1004-1033. doi: 10.1111/j.1582-4934.2009.00697.x

Han HD, Cho YJ, Cho SK, Byeon Y, Jeon HN, Kim HS, Kim BG, Bae DS, Lopez-Berestein G, Sood AK, Shin BC, Park YM, Lee JW (2016) Linalool-incorporated nanoparticles as a novel anticancer agent for epithelial ovarian carcinoma. Mol Cancer Ther 15: 618-627. doi: 10.1158/1535-7163.MCT-15-0733-T

Hao JH, Yu M, Liu FT, Newland AC, Jia L (2004) Bcl-2 Inhibitors Sensitize Tumor Necrosis Factor-Related Apoptosis-Inducing Ligand-Induced Apoptosis by Uncoupling of Mitochondrial Respiration in Human Leukemic CEM Cells. Cancer Res 64: 3607-3616. 10.1158/0008-5472.can-03-3648

Jana S, Patra K, Sarkar S, Jana J, Mukherjee G, Bhattacharjee S, Mandal DP (2014) Antitumorigenic potential of linalool is accompanied by modulation of oxidative stress: an in vivo study in sarcoma-180 solid tumor model. Nutr Cancer 66: 835-848. doi: 10.1080/01635581.2014.904906

Kuwana T, Mackey MR, Perkins G, Ellisman MH, Latterich M, Schneiter R, Green DR, Newmeyer DD (2002) Bid, Bax, and lipids cooperate to form supramolecular openings in the outer mitochondrial membrane. Cell 111: 331-342. doi: 10.1016/S0092-8674(02)01036-X

Letizia CS, Cocchiara J, Lalko J, Api AM (2003) Fragrance material review on linalool. Food Chem Toxicol 41: 943-964. doi: 10.1016/ S0278-6915(03)00015-2

Lindsten T, Ross AJ, King A, Zong WX, Rathmell JC, Shiels HA, Ulrich E, Waymire KG, Mahar P, Frauwirth K, Chen Y, Wei M, Eng VM, Adelman DM, Simon MC, Ma A, Golden JA, Evan G, Korsmeyer SJ, MacGregor GR, Thompson CB (2000) The combined functions of proapoptotic Bcl-2 family members bak and bax are essential for normal development of multiple tissues. Mol Cell 6: 1389-1399. doi: 10.1016/S1097-2765(00)00136-2

Louis DN, Ohgaki H, Wiestler OD, Cavenee WK, Burger PC, Jouvet A, Scheithauer BW, Kleihues P (2007) The 2007 WHO classification of tumours of the central nervous system. Acta Neuropathol 114: 97-109. doi:10.1007/s00401-007-0243-4

Mimica-Dukic N, Bugarin D, Grbovic S, Mitic-Culafic D, VukovicGacic B, Orcic D, Jovin E, Couladis M (2010) Essential oil of Myrtus communis $\mathrm{L}$. as a potential antioxidant and antimutagenic agents. Molecules 15: 2759-2770. doi: 10.3390/molecules15042759

Nakazato Y (2008) The 4th Edition of WHO Classification of Tumours of the Central Nervous System published in 2007. No Shinkei Geka 36: 473-491. doi: 10.11477/mf.1436100746

Ohgaki H (2009) Epidemiology of brain tumors. Methods Mol Biol 472: 323-342. doi: 10.1007/978-1-60327-492-0_14 
Omuro A, DeAngelis LM (2013) Glioblastoma and other malignant gliomas: a clinical review. JAMA 310: 1842-1850. doi: 10.1001/ jama.2013.280319

Ostrom QT, Gittleman H, Farah P, Ondracek A, Chen Y, Wolinsky Y, Stroup NE, Kruchko C, Barnholtz-Sloan JS (2013) CBTRUS statistical report: Primary brain and central nervous system tumors diagnosed in the United States in 2006-2010. Neuro Oncol (Suppl 2): ii1-ii56. doi: 10.1093/neuonc/not151

Paik SY, Koh KH, Beak SM, Paek SH, Kim JA (2005) The essential oils from Zanthoxylum schinifolium pericarp induce apoptosis of HepG2 human hepatoma cells through increased production of reactive oxygen species. Biol Pharm Bull 28: 802-807. doi: 10.1248/ bpb. 28.802

Peana AT, D'Aquila PS, Chessa ML, Moretti MD, Serra G, Pippia P (2003) (-)-Linalool produces antinociception in two experimental models of pain. Eur J Pharmacol 460: 37-41. doi: 10.1016/S00142999(02)02856-X

Peana AT, D'Aquila PS, Panin F, Serra G, Pippia P, Moretti MD (2002) Anti-inflammatory activity of linalool and linalyl acetate constituents of essential oils. Phytomedicine 9: 721-726. doi:10.1078/094471102321621322

Pi H, Xu S, Reiter RJ, Guo P, Zhang L, Li Y, Li M, Cao Z, Tian L, Xie J, Zhang R, He M, Lu Y, Liu C, Duan W, Yu Z, Zhou Z (2015) SIRT3-SOD2-mROS-dependent autophagy in cadmiuminduced hepatotoxicity and salvage by melatonin. Autophagy 11: 1037-1051. doi: 10.1080/15548627.2015.1052208

Qiu X, Brown K, Hirschey MD, Verdin E, Chen D (2010) Calorie restriction reduces oxidative stress by SIRT3-mediated SOD2 activation. Cell Metab 12: 662-667. doi: 10.1016/j.cmet.2010.11.015

Russo R, Ciociaro A, Berliocchi L, Cassiano MG, Rombola L, Ragusa S, Bagetta G, Blandini F, Corasaniti MT (2013) Implication of limonene and linalyl acetate in cytotoxicity induced by bergamot essential oil in human neuroblastoma cells. Fitoterapia 89: 48-57. doi: 10.1016/j.fitote.2013.05.014

Salvesen, GS (2002) Caspases and apoptosis. Essays Biochem 38: 9-19. doi: 10.1042/bse0380009
Stennicke HR, Jurgensmeier JM, Shin H, Deveraux Q, Wolf BB, Yang X, Zhou Q, Ellerby HM, Ellerby LM, Bredesen D, Green DR, Reed JC, Froelich CJ, Salvesen GS (1998) Pro-caspase-3 is a major physiologic target of caspase-8. J Biol Chem 273: 27084-27090. doi: 10.1074/jbc.273.42.27084

Stupp R, Hegi ME, Mason WP, van den Bent MJ, Taphoorn MJ, Janzer RC, Ludwin SK, Allgeier A, Fisher B, Belanger K, Hau P, Brandes AA, Gijtenbeek J, Marosi C, Vecht CJ, Mokhtari K, Wesseling $\mathrm{P}$, Villa S, Eisenhauer E, Gorlia T, Weller M, Lacombe D, Cairncross JG, Mirimanoff RO (2009) Effects of radiotherapy with concomitant and adjuvant temozolomide versus radiotherapy alone on survival in glioblastoma in a randomised phase III study: 5-year analysis of the EORTC-NCIC trial. Lancet Oncol 10: 459-466. doi: 10.1016/S1470-2045(09)70025-7

Tao NN, Zhou HZ, Tang H, Cai XF, Zhang WL, Ren JH, Zhou L, Chen X, Chen K, Li WY, Liu B, Yang QX, Cheng ST, Huang LX, Huang AL, Chen J (2016) Sirtuin 3 enhanced drug sensitivity of human hepatoma cells through glutathione S-transferase pi $1 / \mathrm{JNK}$ signaling pathway. Oncotarget 7: 50117-50130. doi: 10.18632/oncotarget.10319

Usta J, Kreydiyyeh S, Knio K, Barnabe P, Bou-Moughlabay Y, Dagher S (2009) Linalool decreases HepG2 viability by inhibiting mitochondrial complexes I and II, increasing reactive oxygen species and decreasing ATP and GSH levels. Chem Biol Interact 180: 39-46. doi: 10.1016/j.cbi.2009.02.012

Vigneswaran K, Neill S, Hadjipanayis CG (2015) Beyond the World Health Organization grading of infiltrating gliomas: advances in the molecular genetics of glioma classification. Ann Transl Med 3: 95. doi: 10.3978/j.issn.2305-5839.2015.03.57

Weller M, Cloughesy T, Perry JR, Wick W (2013) Standards of care for treatment of recurrent glioblastoma - are we there yet? Neuro Oncol 15: 4-27. doi: $10.1093 /$ neuonc/nos 273

Youle RJ, Strasser A (2008) The BCL-2 protein family: opposing activities that mediate cell death. Nat Rev Mol Cell Biol 9: 47-59. doi:10.1038/nrm230 